\title{
ПРОБЛЕМА ФОРМИРОВАНИЯ СИСТЕМЫ ПОКАЗАТЕЛЕЙ УСТОЙЧИВОГО РАЗВИТИЯ ПРЕДПРИЯТИЯ
}

\author{
(c) 2021 Арошидзе Алёна Амирановна \\ кандидат экономических наук \\ Сибирский государственный университет путей сообщения, Россия, Новосибирск \\ E-mail: aroshidzealyona@gmail.com
}

Выбор показателей и их выстраивание в определенную систему, увязанную с поставленными целями, является основой для выполнения всех управленческих функций на предприятии, начиная с планирования и заканчивая контролем. В данной статье проведен анализ различных систем показателей, посредством которых представляется возможным дать наиболее полную характеристику устойчивого развития предприятия.

Ключевые слова: устойчивое развитие, виды устойчивости, показатели, группировка, подходы

Формирование системы показателей устойчивого развития предприятия должно осуществляться в соответствии с его авторской интерпретацией, хотя некоторые авторы раскрывают содержательные характеристики устойчивого развития как раз только на этапе оценки. При этом показатели фактически характеризуют устойчивое развитие по его составляющим. $\mathrm{K}$ ним, как правило, относятся экономическая, экологическая, социальная компоненты. В авторском понимании в их число также входит и информационная составляющая, преобразующая традиционную триаду устойчивого развития в тетраду.

В целом проведенный анализ показал, что следует выделять три ключевые подхода, в рамках которых авторы формируют системы показателей устойчивого развития предприятия.

Первый подход основывается на их явном разделении по видам устойчивости в случае, если авторы определяют их в контексте устойчивого развития, или просто по его составляющим в разрезе подсистем предприятия.

Так, основываясь на выделенных составляющих устойчивого развития, формирует систему показателей Кондаурова Д.С. В ее понимании финансовая составляющая должна рассматриваться через коэффициенты текущей ликвидности, автономии, финансовой зависимости, маневренности, постоянного актива, обеспеченности собственными средствами, покрытия процентов и мультипликатор собственного капитала. Маркетинговая составляющая представлена коэффициентами изменения объема продаж, маркетинговых затрат, долей рынка, количеством оборотов товарных запасов. К производственной составляющей отнесены коэффициент производственной устойчивости, рентабельность производства, фондоотдача, к технологической составляющей - коэффициенты годности оснастки и технических средств, обновления и прироста основных средств. Для характеристики организационной составляющей устойчивого развития автор прибегает к коэффициентам эффективности управления, экономичности организационной структуры, безубыточности управленческой деятельности. Инвестиционная составляющая определяется посредством коэффициентов инвестиционной активности, инвестиций в основной капитал, инвестиций в НИОКР, финансовых инвестиций $[1,6]$.

Хомяченкова Н.А., рассматривая устойчивое развитие предприятия, прибегает полностью к аналогичной систематизации и составу показателей, что и Кондаурова Д.С., однако выделяет также показатели социальной, экологической и рисковой устойчивости. Социальная устойчивость охарактеризована с помощью таких показателей, как коэффициенты стабильности кадров, отношения средней заработной платы к средней по отрасли, обеспеченности нормальных условий труда, задолженности по заработной плате. Экологическая устойчивость представлена коэффициентами ресурсосберегающих технологий, загрязнения окружающей среды, природоохранных мероприятий, природоемкости, рисковая устойчивость - показателями внутренней и внешней устойчивости предприятия к риску [5, с.66].

В рамках второго подхода авторы формиру- 
ют систему показателей, разбивая их на группы, но не по видам устойчивостей или конкретным подсистемам предприятия. В ряде случаев наблюдается их объединение между собой и/или использование нескольких классификационных признаков в рамках одной системы показателей. Кроме того, к сторонникам данного подхода можно отнести тех авторов, которые использует определенные категории (например, потенциал, эффективность, конкурентоспособность и пр.), индикаторы, факторы, складывающиеся отношения внутри и за пределами предприятия для характеристики устойчивого развития.

Так, в понимании Батыровой Н.С. в контексте устойчивого развития экономическая эффективность представлена совокупным акционерным доходом, рентабельностью продаж, выручкой, EBITDA, технологическая результативность - объемом инвестирования, его эффективностью, долей инновационных технологий, сертификатами качества, ожидаемым экономическим эффектом и сроком окупаемости, долей сырья от внешних поставщиков в общем объеме материальных затрат, механизацией и автоматизацией производства, продуктивностью, экологическая безопасность - экономией энергии в год, социальная устойчивость - добавленной стоимостью, текучестью кадров, среднегодовым фондом оплаты труда, среднемесячной заработной платой, расходами на обучение и повышение квалификации, расходами на нематериальную мотивацию персонала, социальными льготами, эффективные отношения со связанными сторонами - результатами аудита, организационная эффективность - коэффициентом энтропии, степенью вертикальной интеграции [2, с. 21-22].

Глеков П.М. предлагает характеризовать устойчивое развитие предприятия в разрезе рентабельности (рентабельность всех активов, текущих активов, продаж, продукции), оборачиваемости активов (соответствующий коэффициент), финансовой устойчивости (коэффициенты автономии, финансовой устойчивости, маневренности собственных средств), ликвидности (коэффициенты текущей, критической, абсолютной ликвидности), характеристики производства (коэффициенты износа, обновления, выбытия основных средств, фондоёмкости продукции) [7, с. 229-230].

В соответствии с третьим подходом формирование системы показателей устойчивого развития предприятия осуществляется без их разделения на определенные группы. При этом сформированная система может включать в себя как достаточно разнообразные показатели, которые, по сути, отражают различные аспекты деятельности предприятия, так и характеризоваться явным акцентом на определенной сфере - например, финансовой.

В контексте устойчивого развития предприятия Власова Н.В. предлагает использовать такие показатели, как коэффициенты абсолютной ликвидности, покрытия, текущей ликвидности, соотношения собственных и заемных средств, рентабельности продукции [3, с.9], ВоронцоваЕ.И. прибегает к показателям темпов роста выручки от продаж, инвестиций, средних доходов на одного работающего [4, с.14].

Более масштабная система показателей сформирована ЯруллинойГ.Р., которая выделяет чистую прибыль, прибыль от продаж, выручку от реализации продукции, себестоимость реализованной продукции, оборотные активы, собственный капитал, совокупный капитал, основные средства, активную часть основных средств, дебиторскую задолженность, запасы, кредиторскую задолженность, среднесписочную численность работников, затраты на оплату труда, материальные затраты, затраты на энергию, амортизационные отчисления в составе затрат [8, с. 198].

Проведенный анализ авторских систем показателей, некоторые результаты которого приведены в данной статье, позволил сделать вывод, что существует целый пласт показателей, который используется, как правило, для предприятий всех размеров и сфер деятельности и не относится к числу единичного упоминания. Однако это не означает, что данные показатели употребляются для характеристики устойчивого развития всех рассматриваемых категорий предприятий с одинаковой частотой. В этой связи предлагается резюмировать проблематику формирования системы показателей устойчивого развития посредством определения частоты их использования в зависимости от размеров предприятий и сфер осуществления их деятельности.

В таблице 1 представлены результаты анализа систем показателей экономической составляющей устойчивого развития различных предприятий, в таблицах 2-3 - социальной и экологической компоненты соответственно. 
Таблица 1. Частота использования некоторых показателей экономической составляющей устойчивого развития предприятий

\begin{tabular}{|c|c|c|c|}
\hline Показатели & Наибольшая частота & Средняя частота & Низкая частота \\
\hline текущая ликвидность & $\begin{array}{l}\text { крупные, СМП промыш- } \\
\text { ленные, крупные, СМП } \\
\text { строительные, крупные, } \\
\text { СМП сфера услуг }\end{array}$ & крупные, СМП АПК & - \\
\hline рентабельность активов & $\begin{array}{l}\text { крупные, СМП промыш- } \\
\text { ленные, крупные, СМП } \\
\text { АПК, крупные сфера } \\
\text { услуг, крупные, СМП стро- } \\
\text { ительные }\end{array}$ & СМП сфера услуг & - \\
\hline $\begin{array}{l}\text { обеспеченность собствен- } \\
\text { ными средствами }\end{array}$ & $\begin{array}{l}\text { крупные, СМП промыш- } \\
\text { ленные, крупные, СМП } \\
\text { АПК, СМП сфера услуг, } \\
\text { крупные, СМП строитель- } \\
\text { ные }\end{array}$ & крупные сфера услуг & - \\
\hline $\begin{array}{l}\text { коэффициент обновления } \\
\text { основных фондов }\end{array}$ & $\begin{array}{l}\text { крупные, СМП промыш- } \\
\text { ленные, крупные, СМП } \\
\text { АПК }\end{array}$ & - & $\begin{array}{l}\text { крупные, СМП сфера } \\
\text { услуг, строительные }\end{array}$ \\
\hline $\begin{array}{l}\text { коэффициент использо- } \\
\text { вания производственной } \\
\text { мощности }\end{array}$ & $\begin{array}{l}\text { крупные промышленные, } \\
\text { крупные, СМП строитель- } \\
\text { ные }\end{array}$ & СМП промышленные & $\begin{array}{l}\text { крупные, СМП сфера } \\
\text { услуг, АПК }\end{array}$ \\
\hline доля рынка & $\begin{array}{l}\text { крупные, СМП промыш- } \\
\text { ленные }\end{array}$ & - & $\begin{array}{l}\text { крупные, СМП сфера } \\
\text { услуг, АПК }\end{array}$ \\
\hline $\begin{array}{l}\text { изменение объема про- } \\
\text { даж }\end{array}$ & $\begin{array}{l}\text { крупные промышленные, } \\
\text { крупные АПК, крупные, } \\
\text { СМП сфера услуг }\end{array}$ & СМП промышленные & $\begin{array}{l}\text { СМП АПК, крупные, СМП } \\
\text { строительные }\end{array}$ \\
\hline $\begin{array}{l}\text { рентабельность произ- } \\
\text { водства }\end{array}$ & $\begin{array}{l}\text { крупные, СМП промыш- } \\
\text { ленные }\end{array}$ & - & $\begin{array}{l}\text { крупные, СМП строитель- } \\
\text { ные, АПК, сфера услуг }\end{array}$ \\
\hline фондоотдача & $\begin{array}{l}\text { крупные, СМП промыш- } \\
\text { ленные, крупные АПК, } \\
\text { крупные, СМП строитель- } \\
\text { ные }\end{array}$ & $\begin{array}{l}\text { СМП АПК, крупные сфера } \\
\text { услуг }\end{array}$ & СМП сфера услуг \\
\hline $\begin{array}{l}\text { производительность } \\
\text { труда }\end{array}$ & $\begin{array}{l}\text { крупные промышленные, } \\
\text { крупные, СМП АПК, круп- } \\
\text { ные, СМП строительные }\end{array}$ & $\begin{array}{l}\text { СМП промышленные, } \\
\text { крупные, СМП сфера } \\
\text { услуг }\end{array}$ & - \\
\hline $\begin{array}{l}\text { коэффициент маневрен- } \\
\text { ности }\end{array}$ & СМП сфера услуг & крупные промышленные & $\begin{array}{l}\text { СМП промышленные, } \\
\text { крупные, СМП АПК, круп- } \\
\text { ные, СМП строительные, } \\
\text { крупные сфера услуг }\end{array}$ \\
\hline $\begin{array}{l}\text { инвестиционная актив- } \\
\text { ность }\end{array}$ & $\begin{array}{l}\text { крупные, СМП строитель- } \\
\text { ные }\end{array}$ & $\begin{array}{l}\text { крупные промышленные, } \\
\text { крупные, СМП АПК }\end{array}$ & $\begin{array}{l}\text { СМП промышленные, } \\
\text { крупные, СМП сфера } \\
\text { услуг }\end{array}$ \\
\hline
\end{tabular}


Таблица 2. Частота использования показателей социальной составляющей устойчивого развития предприятий

\begin{tabular}{|c|c|c|c|}
\hline Показатели & Наибольшая частота & Средняя частота & Низкая частота \\
\hline $\begin{array}{l}\text { коэффициент стабильно- } \\
\text { сти кадров }\end{array}$ & $\begin{array}{l}\text { крупные, СМП промыш- } \\
\text { ленные, крупные, СМП } \\
\text { АПК, строительные, сфера } \\
\text { услуг }\end{array}$ & - & - \\
\hline $\begin{array}{l}\text { отношение заработной } \\
\text { платы к средней по отрас- } \\
\text { ли (региону) }\end{array}$ & $\begin{array}{l}\text { крупные промышленные, } \\
\text { крупные АПК }\end{array}$ & $\begin{array}{l}\text { СМП промышленные, } \\
\text { СМП АПК, крупные, СМП } \\
\text { строительные }\end{array}$ & $\begin{array}{l}\text { крупные, СМП сфера } \\
\text { услуг }\end{array}$ \\
\hline $\begin{array}{l}\text { коэффициент профессио- } \\
\text { нальной подготовки }\end{array}$ & СМП промышленные & крупные промышленные & $\begin{array}{l}\text { крупные, СМП АПК, стро- } \\
\text { ительные, сфера услуг }\end{array}$ \\
\hline текучесть кадров & - & крупные промышленные & $\begin{array}{l}\text { СМП промышленные, } \\
\text { крупные, СМП АПК, стро- } \\
\text { ительные, сфера услуг }\end{array}$ \\
\hline $\begin{array}{l}\text { задолженность по зара- } \\
\text { ботной плате }\end{array}$ & - & - & $\begin{array}{l}\text { крупные, СМП промыш- } \\
\text { ленные, крупные, СМП } \\
\text { АПК, строительные, сфера } \\
\text { услуг }\end{array}$ \\
\hline $\begin{array}{l}\text { обеспеченность нормаль- } \\
\text { ными условиями труда }\end{array}$ & крупные, СМП АПК & - & $\begin{array}{l}\text { крупные, СМП промыш- } \\
\text { ленные, строительные, } \\
\text { сфера услуг }\end{array}$ \\
\hline кадровая обеспеченность & - & - & $\begin{array}{l}\text { крупные, СМП промыш- } \\
\text { ленные, строительные, } \\
\text { АПК, сфера услуг }\end{array}$ \\
\hline $\begin{array}{l}\text { отношение приема и } \\
\text { выбытия работников }\end{array}$ & - & - & $\begin{array}{l}\text { крупные, СМП промыш- } \\
\text { ленные, строительные, } \\
\text { АПК, сфера услуг }\end{array}$ \\
\hline $\begin{array}{l}\text { отношение заработной } \\
\text { платы к прожиточному } \\
\text { минимуму }\end{array}$ & - & - & $\begin{array}{l}\text { крупные, СМП промыш- } \\
\text { ленные, строительные, } \\
\text { АПК, сфера услуг }\end{array}$ \\
\hline
\end{tabular}

Таблица 3. Частота использования показателей экологической составляющей устойчивого развития предприятий

\begin{tabular}{|c|c|c|c|}
\hline Показатели & Наибольшая частота & Средняя частота & Низкая частота \\
\hline $\begin{array}{l}\text { коэффициент загрязне- } \\
\text { ния окружающей среды }\end{array}$ & $\begin{array}{l}\text { крупные промышленные, } \\
\text { крупные, СМП АПК }\end{array}$ & СМП промышленные & $\begin{array}{l}\text { крупные, СМП АПК, стро- } \\
\text { ительные }\end{array}$ \\
\hline $\begin{array}{l}\text { коэффициент природоох- } \\
\text { ранных мероприятий }\end{array}$ & крупные промышленные & - & $\begin{array}{l}\text { СМП промышленные, } \\
\text { крупные, СМП АПК, сфера } \\
\text { услуг, строительные }\end{array}$ \\
\hline удельный вес отходов & $\begin{array}{l}\text { крупные промышленные, } \\
\text { крупные, СМП АПк }\end{array}$ & - & $\begin{array}{l}\text { СМП промышленные, } \\
\text { крупные, СМП строитель- } \\
\text { ные }\end{array}$ \\
\hline динамика штрафов & крупные промышленные & - & $\begin{array}{l}\text { СМП промышленные, } \\
\text { крупные, СМП АПК, сфера } \\
\text { услуг, строительные }\end{array}$ \\
\hline $\begin{array}{l}\text { коэффициент экологич- } \\
\text { ности }\end{array}$ & - & крупные промышленные & $\begin{array}{l}\text { СМП промышленные, } \\
\text { крупные, СМП АПК, сфера } \\
\text { услуг, строительные }\end{array}$ \\
\hline $\begin{array}{l}\text { коэффициент природо- } \\
\text { емкости }\end{array}$ & СМП промышленные & крупные промышленные & $\begin{array}{l}\text { крупные, СМП АПК, сфера } \\
\text { услуг, строительные }\end{array}$ \\
\hline $\begin{array}{l}\text { коэффициент финанси- } \\
\text { рования экологической } \\
\text { безопасности (техноло- } \\
\text { гий) }\end{array}$ & - & крупные промышленные & $\begin{array}{l}\text { СМП промышленные, } \\
\text { крупные, СМП АПК, стро- } \\
\text { ительные }\end{array}$ \\
\hline энергоемкость & крупные АПК & - & $\begin{array}{l}\text { СМП АПК, крупные, СМП } \\
\text { промышленные, сфера } \\
\text { услуг, строительные }\end{array}$ \\
\hline $\begin{array}{l}\text { коэффициент эффектив- } \\
\text { ности ресурсоемкости }\end{array}$ & - & - & $\begin{array}{l}\text { крупные, СМП промыш- } \\
\text { ленные, АПК, сфера услуг, } \\
\text { строительные }\end{array}$ \\
\hline
\end{tabular}


Рассмотренные показатели наименее вариабельны по частоте использования для предприятий сферы услуг, строительства, а также чуть в большей степени для сельскохозяйственный предприятий. В данном контексте под этим понимается, что для характеристики устойчивого развития данных предприятий показатели применяются в большинстве случае либо с высокой, либо с низкой частотой. Говоря составляющих в контексте устойчивого развития, аналогичными тенденциями, т.е. наименьший вариабельностью, характеризуются показатели социальной и экологической детерминанты.

Таким образом, полученные и систематизи- рованные результаты дают представление о тенденциях формирования системы показателей, характеризующих устойчивое развитие предприятий различных размеров и сфер деятельности, а также позволяют на этой основе сформировать собственную систему показателей как отдельно по определенным видам устойчивости, так и в целом. Однако необходимо понимать, что практическое значение сформированной системы показателей заключается в ее применении для проведения оценки, разработки и принятия на ее основе результативных управленческих решений на предприятиях.

\section{Библиографический список}

1. Арошидзе А.А.Теория и методология управления экономической составляющей устойчивого развития предпринимательских структур: монография. - Новосибирск: Изд. ООО «СибАК», 2019. - 194 с.

2. Батырова Н.С. Методологические основы разработки и реализации стратегии устойчивого развития хозяйствующего субъекта / Н.С.Батырова // Экономический анализ: теория и практика.- 2014.- № 44 (395). - C.14-25.

3. Власова Н.В.Формирование механизмов управления устойчивым развитием экономики промышленных предприятий: автореферат дис. ... кандидата экономических наук: 08.00.05 / Власова Наталья Владимировна. - Владимир. гос. ун-т.- Владимир, 2005. - 27 с.

4. Воронцова Е.И. Формирование механизмов устойчивого развития промышленных комплексов с учетом глобализации мировой экономики: автореферат дис. ... кандидата экономических наук: 08.00.05 / Воронцова Елена Ивановна. - Воронеж, 2014.- 24 с.

5. Горшенина Е.В., Хомяченкова Н.А.Мониторинг устойчивого развития промышленного предприятия / Е. В. Горшенина, Н. А. Хомяченкова // Российское предпринимательство. - 2011. - Том 12.- № 1.- С. 63-67.

6. Кондаурова, Д. С. Развитие инструментария оценки уровня устойчивого развития современной организации / Д.С. Кондаурова // Вопросы современной науки: проблемы, тенденции и перспективы: материалы I Междунар. науч.-практ. конф., 31 июля 2015 г.: сб. науч. тр. / науч. ред. Ю. В. Мамченко.- М.: Перо, 2015.C. 87-99.

7. Формирование новой экономики и кластерные инициативы: теория и практика / под ред. д-ра экон. наук, проф. А. В.Бабкина. - СПб.: Изд-во Политехн. ун-та, 2016. - 516 с.

8. Яруллина Г.Р. Динамическая модель мониторинга устойчивого экономического развития промышленного предприятия / Г. Р. Яруллина // Аудит и финансовый анализ. - 2012. - № 6. - С.195-202. 